[Miscellaneous Note]

\section{Hand-made trunk-injector for assaying candidates for trunk-injection agents against the pinewood nematode}

\author{
Nobuo Ogura ${ }^{1}$
}

The pine wilt disease is caused by infestation of the pinewood nematode, Bursaphelenchus xylophilus (Steiner and Buhrer) Nickle (Mamiya, 1986). One of practical control methods for the disease is prophylactic application of a trunkinjection agent against the pinewood nematode (Matsuura and Kobayashi, 1976; Takai et al., 2000) and ampoule type injectors are used. In this miscellaneous note, a hand-made trunkinjector for assaying candidates for the agent was developed.

Hand-made injector:

The container was a $500 \mathrm{ml}$ - polyethylene terephthalate (PET) beverage bottle. A hole (dia. $6.5 \mathrm{~mm}$ ) was made in the middle of the bottle screw cap using an electric drill (Fig. 1. A). An outer tube of $1 \mathrm{ml}$ tuberculin syringe (length ca $8.4 \mathrm{~cm}$, dia. ca $6.7 \mathrm{~mm}$ ) (Nipro Co., Japan) was inserted into the hole. Polyvinyl chloride adhesive (Bond for gutter, Konishi Co., Japan) was applied to the syringe tube (Fig. 1. B) and then it was completely inserted into the hole.

The tip of the syringe tube was cut off and inserted into a soft-polyvinyl chloride-tube (inner $\times$ outer dia. $5 \times 7 \mathrm{~mm}$, length ca $25 \mathrm{~cm}$ ) (Labo.Tube ${ }^{\circledR}$, Iuchi Co., Japan) (Fig. 1. C. a). Polytetrafluoroethylene (PTFE) resin pipe (inner $\times$ outer dia. $4 \times 6 \mathrm{~mm}$, length ca $12 \mathrm{~cm})(4$ - flu-

${ }^{1}$ Forestry and Forest Products Institute, PO Box 16, Tsukuba Norin danchi, Tsukuba city, Ibaraki 305-8687, Japan. orate pipe ${ }^{\circledR}$, Iuchi Co., Japan) (Fig. 1 C. b) was inserted into the opposite end of the softpolyvinyl chloride-tube. Joints between 4-fluorate pipe and soft-polyvinyl chloride-tube, between soft-polyvinyl chloride-tube and syringe tube and between syringe and plug were wound with polyvinyl chloride-tape (width $2 \mathrm{~cm}$, length ca $5 \mathrm{~cm}$ ) to prevent them from slipping out (Fig. 1. D). Packing (dia. $26.5 \mathrm{~mm}$ ) was made of synthetic rubber board (thickness ca $2 \mathrm{~mm}$ ) (Viton board ${ }^{\circledR}$, Dupont Dow Elastomers Japan Co., Japan) (Fig. 1. E). A hole (dia. ca $5 \mathrm{~mm}$ ) was made in the middle of the packing and then the packing was put into the screw cap. The 4-fluorate pipe was wrapped with seal tape (PTFE, thickness 0.1 , wide 13 , length $50 \mathrm{~mm}$ ) and the anterior end was split (Fig. 1. F).

Injection method:

A candidate for trunk-injection agent was poured into the injector container. The injector container was capped. The soft-polyvinyl chloride-tube of the injector was clipped with a paper clip. The 4-fluorate pipe of the injector was inserted into a hole (dia. $6.0 \mathrm{~mm}$, depth ca 5 $\mathrm{cm}$ ) which was made in the pine trunk using a hand drill. Angle of the hole to trunk was ca $45^{\circ}$. A small hole was then made on top of the injector (bottom of PET bottle) using an eyeleteer (Fig. 1. G). The paper clip was removed at beginning of injection. In this way, the candidate was able to be injected into the pine trees.

\section{ACKNOWLEGDEMENT}

I thank Dr. J. T. Gaspard, a member of the Japanese Nematological Society, for reviewing the manuscript.

\section{LITERATURE CITED}

Mamiya, Y. (1986) The pine wood nematode. In: Plant and insect nematodes, pp.589-626. Ed. Nickle, W. R. Marcel Dekker, Inc. New York and Basel, 925 pp. 
Matsuura, K. and Kobayashi, T. (1976) Trunk injection to pine tree and soil treatment around pine tree with several compounds. Forest Pest 25, 207-210. (in Japanese)

Takai, K.., Soejima, T., Suzuki, T. and Kawazu,
K. (2000) Emamectin benzoate as a candidate for a trunk-injection agent against the pine wood nematode, Bursaphelenchus xylophilus. Pest Management Science 56, 937-941.

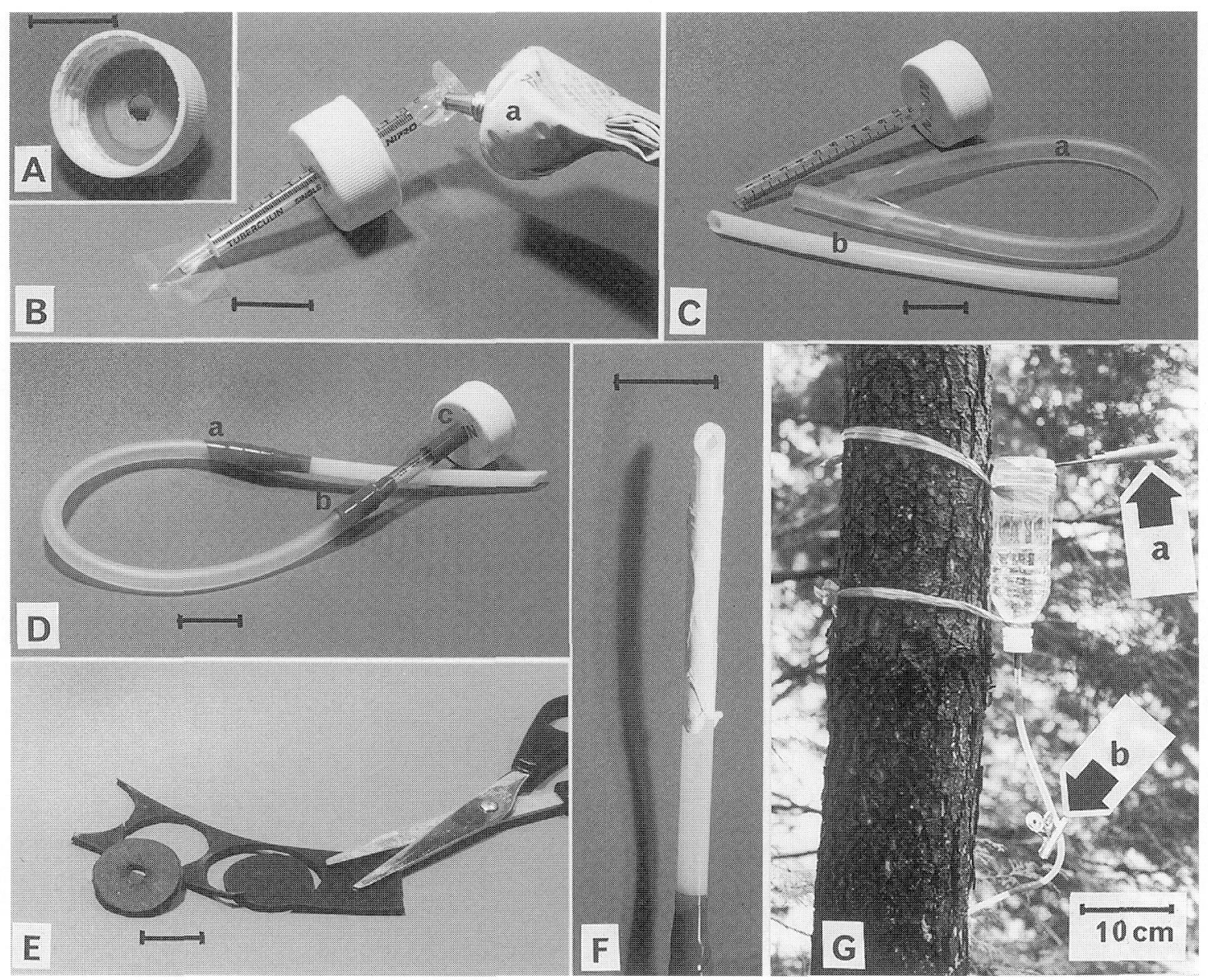

Fig. 1. A: Screw cap with a hole. B: Polyvinyl chloride adhesive (a) applied to outer tube of syringe. C: Soft-polyvinyl chloride-tube (a) and polytetrafluoroethylene (PTFE) resin pipe (b). D: Joints (a, b and c) wound with polyvinyl chloride-tape. E: Packing made of a synthetic rubber board. F: 4-fluorate pipe wrapped with seal tape. G: Injection of candidate for trunk-injection agent into pine tree. Eyeleteer (a) and paper clip (b) were removed at beginning of injection. Bars in A-F indicate $2 \mathrm{~cm}$. 